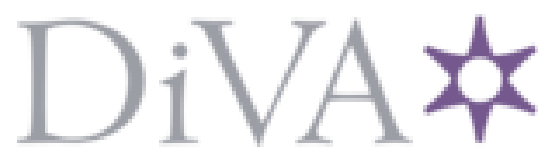

http://www.diva-portal.org

This is the published version of a paper published in Organic Letters.

Citation for the original published paper (version of record):

van der Werf, A., Selander, N. (2015)

Para-Selective Halogenation of Nitrosoarenes with Copper(II) Halides.

Organic Letters, 17(24): 6210-6213

http://dx.doi.org/10.1021/acs.orglett.5b03198

Access to the published version may require subscription.

N.B. When citing this work, cite the original published paper.

Permanent link to this version:

http://urn.kb.se/resolve?urn=urn:nbn:se:su:diva- 126203 


\title{
Para-Selective Halogenation of Nitrosoarenes with Copper(II) Halides
}

\author{
Angela van der Werf and Nicklas Selander* \\ Department of Organic Chemistry, Arrhenius Laboratory, Stockholm University, SE-106 91 Stockholm, Sweden
}

\section{Supporting Information}

ABSTRACT: The para-selective direct bromination and chlorination of nitrosoarenes with copper(II) bromide and chloride is reported. Under mild reaction conditions, a range of halogenated arylnitroso compounds are obtained in moderate to good yields with high regioselectivity. Additionally, the versatility of the method is demonstrated by the development of a one-pot procedure to obtain the corresponding para-halogenated aniline- and nitrobenzene derivatives.

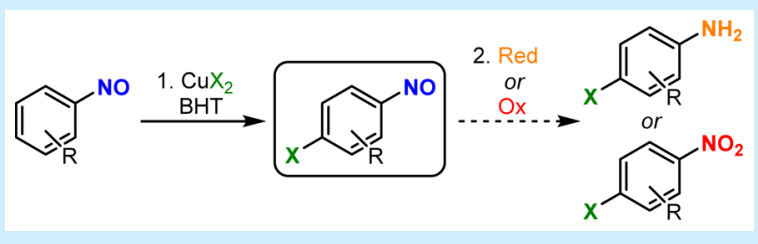

A rylnitroso compounds are versatile building blocks that can undergo a broad range of transformations. ${ }^{1}$ Moreover, nitroso compounds are readily synthesized by nitrosation ${ }^{2}$ or by redox reactions ${ }^{3}$ of nitrogen-containing starting materials. Most of the known transformations of arylnitroso compounds are operating on the nitroso group itself, with addition, ${ }^{4} \mathrm{~N}$ - or $\mathrm{O}$ nitroso aldol, ${ }^{5}$ annulation, and cycloaddition, ${ }^{6}$ and nitroso-ene ${ }^{7}$ reactions being the most important examples. Additionally, the nitroso group can easily be reduced or oxidized to obtain amines, hydroxylamines, or nitro compounds. ${ }^{1 \mathrm{~d}}$ In contrast, there are far fewer examples of aromatic functionalization reactions of nitrosoarenes. $^{8-10}$

Given the wide applicability of halogenated aromatics, the development of regioselective halogenation methods has received considerable attention. ${ }^{11-13}$ Conveniently, the use of $\mathrm{Cu}$ (II) salts ${ }^{12,13}$ has been devised as a mild and selective alternative to classical methods, both by organometallic pathways ( $\mathrm{C}-\mathrm{H}$ functionalization, ortho-directing) and by oxidative methods (for electron-rich arenes, para-directing). ${ }^{13 \mathrm{k}}$ Interestingly, the electron-withdrawing nitroso group has been recognized to be selectively para-directing in the classical halogenation with $\mathrm{Br}_{2}$ and $\mathrm{Cl}_{2}{ }^{8 \mathrm{a}}$ For nitrosobenzene, the parahalogenated product was obtained in yields $\sim 40 \%$ or less. This procedure requires a careful control of the reaction temperature $\left(-5{ }^{\circ} \mathrm{C}\right)$, and a repeated removal of $\mathrm{HX}$ formed. Moreover, azoxyarenes and nitro compounds were formed as byproducts, along with unreacted starting material (Scheme 1a).

Even though this reactivity has been recognized as unique, ${ }^{8 c}$ no other methods for the halogenation of nitrosoarenes have, to the best of our knowledge, been reported. Exploiting the unique reactivity of nitrosoarenes, and with the use of $\mathrm{Cu}$ (II) halides as mild, convenient, and less hazardous alternatives to elemental

Scheme 1. Halogenation of Arylnitroso Compounds

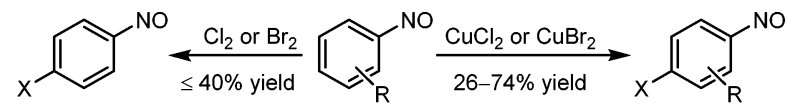

a) Ingold: $\mathrm{R}=\mathrm{H}$ only

b) This work: $\mathrm{R}=\mathrm{H}$, Alkyl, $\mathrm{Ph}, \mathrm{F}, \mathrm{Br}$,
$\mathrm{Cl}_{2} / \mathrm{Br}_{2}$, we herein report on a general and regioselective halogenation method (Scheme 1b) and the subsequent one-pot oxidation/reduction protocol to obtain functionalized anilines, nitrosoarenes, and nitroarenes.

During the initial screening of reaction conditions ${ }^{14}$ for the chlorination of nitrosobenzene (1a) with $\mathrm{CuCl}_{2}$, a number of interesting observations were encountered (Scheme 2).

Scheme 2. Relevant Findings in the Screening of Conditions

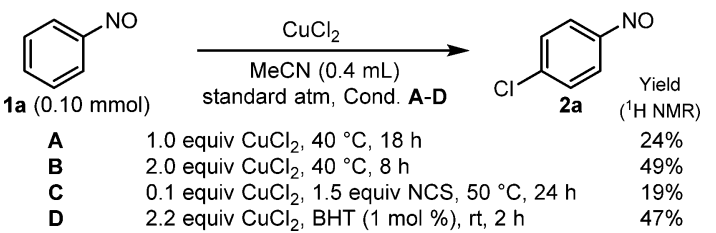

In the presence of 1.0 equiv of $\mathrm{CuCl}_{2}$ in $\mathrm{MeCN}$ at $40{ }^{\circ} \mathrm{C}$, the para-chlorinated nitrosoarene $\mathbf{2 a}$ was obtained as a single regioisomer in $24 \%$ yield (by crude ${ }^{1} \mathrm{H}$ NMR) after $18 \mathrm{~h}$, along with $19 \%$ of unreacted starting material 1a (Scheme 2, conditions A). Upon increasing the loading of $\mathrm{CuCl}_{2}$ to 2.0 equiv, $\sim 90 \%$ conversion of $1 \mathrm{a}$ was observed after $8 \mathrm{~h}$, and the NMR yield of $2 \mathrm{a}$ was $49 \%$ (Scheme 2, conditions B). Around 7\% of azoxyarene was observed, whereas the remainder of the starting material was not accounted for (vide infra). By using $\mathrm{CuCl}_{2}$ in a catalytic amount (10 mol \%) with NCS as an oxidant, $2 \mathrm{a}$ was formed in $19 \%$ yield after $24 \mathrm{~h}$ at $50{ }^{\circ} \mathrm{C}$ (Scheme 2, conditions C). However, a similar yield (17\%) was obtained in the absence of $\mathrm{CuCl}_{2}$, and the use of NCS led to a significant amount of nitrobenzene ( $33 \%$ yield) as a byproduct, demonstrating the need for a mild oxidant, such as $\mathrm{Cu}$ (II) halides.

When a stoichiometric amount of $\mathrm{CuCl}_{2}$ was used (Scheme 2, conditions $\mathrm{A}$ and $\mathrm{B}$ ), a long induction period was observed, which led us to suspect that radicals may be involved. Thus, we investigated the effect of TEMPO (2,2,6,6-tetramethylpiperidin-

Received: November 5, 2015

Published: November 25, 2015 
1-oxyl), $\mathrm{CuCl}$, and BHT (2,6-di-tert-butyl-4-methylphenol) as additives. The addition of $\mathrm{CuCl}$ ( 0.1 equiv) or TEMPO ( 1 equiv) resulted in a complete loss of reactivity, 1a was found to be intact after $18 \mathrm{~h} .{ }^{14}$ However, the addition of BHT $(1 \mathrm{~mol} \%)$ did not only reduce the induction period significantly but also allowed for the reaction to be performed at room temperature. The parachlorinated product $2 \mathrm{a}$ was obtained in $47 \%$ yield by ${ }^{1} \mathrm{H}$ NMR (Scheme 2, conditions D). No conversion was observed without BHT after $24 \mathrm{~h}$ at rt.

In order to improve the yield of the halogenation reaction, several solvents, dilution, slow addition, and a lower reaction temperature were screened. In addition, a number of published halogenation methods were investigated for comparison. None of the efforts led to a more efficient reaction than the use of $\mathrm{Cu}(\mathrm{II})$ halides in a stoichiometric amount; see the Supporting Information (Table S-1) for a selection of reaction conditions investigated. We settled for a general method using 2.2 equiv of the $\mathrm{Cu}$ (II) halide and $1 \mathrm{~mol} \%$ of $\mathrm{BHT}$ and investigated the scope of this transformation. We were pleased to find that the general reaction conditions were applicable for a wide range of substituted nitrosoarenes, yielding the monochlorinated products with high regioselectivity (Scheme 3 ).

Scheme 3. Chlorination of Nitrosoarenes ${ }^{a}$

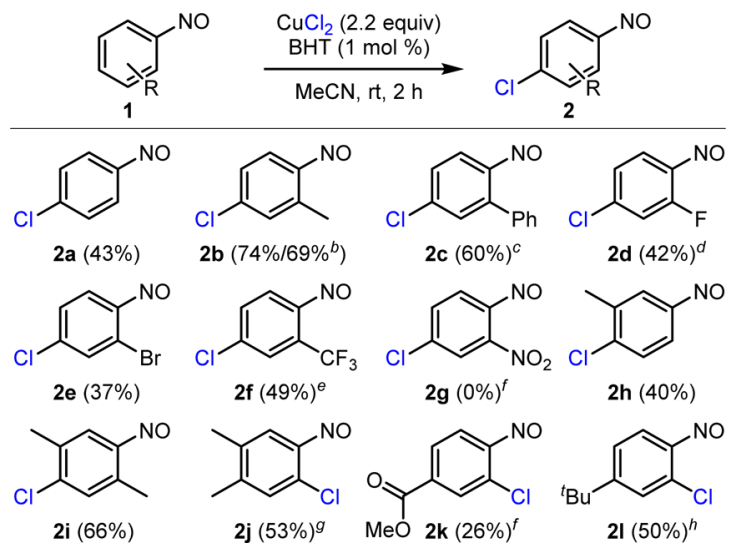

${ }^{a}$ General conditions: nitrosoarene $\mathbf{1}(0.30 \mathrm{mmol}), \mathrm{CuCl}_{2}$ (2.2 equiv), and BHT $(1 \mathrm{~mol} \%)$ in $\mathrm{MeCN}(1.2 \mathrm{~mL}) .{ }^{b} 11.0 \mathrm{mmol}$ scale. ${ }^{c}$ Time: 4 h. ${ }^{d}$ Time: 5 h. ${ }^{e}$ For $7 \mathrm{~h}$ at $50{ }^{\circ} \mathrm{C} .{ }^{f}$ For $24 \mathrm{~h}$ at $50{ }^{\circ} \mathrm{C} .{ }^{g}$ With 2-chloro3,4-dimethyl-1-nitrosobenzene (4:1). ${ }^{h}$ Time: $7 \mathrm{~h}$.

For ortho-substituted nitrosoarenes, para-chlorinated products $\mathbf{2 b}-\mathbf{f}$ were obtained in moderate to high yields depending on the electronic character of the substituent. The highest isolated yield, $74 \%$, was obtained for the $o$-methyl derivative $\mathbf{2 b}$. This reaction was also performed on an $11.0 \mathrm{mmol}$ scale to obtain $1.18 \mathrm{~g}$ of the chlorinated product (69\% yield). The less electron-rich nitrosoarenes were obtained in lower yields and required longer reaction times and/or elevated temperatures (Scheme 3, 2d-f). No reaction was observed in an attempted chlorination of $o$ nitronitrosobenzene (1g). Meta-substituted nitrosoarenes afforded the corresponding products in moderate to good yields $(\mathbf{2} \mathbf{h}-\mathbf{j})$, whereas for the para-substituted substrates, a prolonged reaction time was required, and the products were identified as the ortho-chlorinated nitroso derivatives $2 \mathbf{j}-\mathbf{l}$.

Upon replacing $\mathrm{CuCl}_{2}$ with $\mathrm{CuBr}_{2}$, the analogous parabrominated nitrosoarenes were obtained in comparable yields (Scheme 4). The most important difference was an increased reactivity observed with $\mathrm{CuBr}_{2}$ as exemplified in the bromination of nitrosobenzene (1a), where traces $(\leq 5 \%)$ of the 2,4 -
Scheme 4. Bromination of Nitrosoarenes ${ }^{a}$

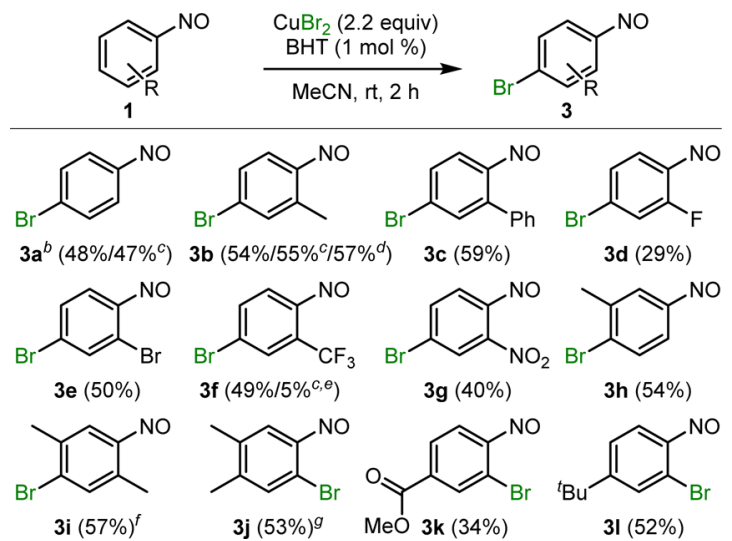

${ }^{a}$ General conditions: Nitrosoarene $1(0.30 \mathrm{mmol}), \mathrm{CuBr}_{2}$ (2.2 equiv), and $\operatorname{BHT}(1 \mathrm{~mol} \%)$ in $\mathrm{MeCN}(1.2 \mathrm{~mL}) .{ }^{b}$ With $\leq 5 \%$ of 1,3 -dibromo4-nitrosobenzene. ${ }^{c}$ With $\mathrm{CuBr}_{2}$ ( 0.1 equiv) and NBS (1.5 equiv) for $24 \mathrm{~h}$ at $50{ }^{\circ} \mathrm{C} .{ }^{d} 11.0 \mathrm{mmol}$ scale, general cond. ${ }^{e 1} \mathrm{H}$ NMR yield. ${ }^{f}$ Time: 1 h. ${ }^{g}$ Time: 5 min, ${ }^{1} \mathrm{H}$ NMR yield, with 2-bromo-3,4-dimethyl-1nitrosobenzene $(3: 1)$.

dibrominated product were observed, and by the short reaction times required for dimethyl-substituted nitrosoarenes $\mathbf{1 i}$ and $\mathbf{1 j}$ to avoid decomposition. In some cases, we observed di- or tribrominated anilines as byproducts $(<10 \%)$. Moreover, the nitro-substituted substrate $\mathbf{1 g}$, which was unreactive in the chlorination (Scheme 3, 2g), was brominated in an acceptable yield $(3 \mathrm{~g}, 40 \%$ yield). This result is remarkable as similar halogenation methods for arenes only work for electron-rich substrates or require directing groups. ${ }^{12,13}$ The bromination was also scalable, giving $3 \mathbf{b}$ in $57 \%$ yield $(1.25 \mathrm{~g})$. The attempted halogenation of $\mathrm{OMe}-, \mathrm{Me}_{2} \mathrm{~N}-, \mathrm{CHO}_{-}$, and acyl-substituted nitrosoarenes led to an intractable mixture of products. When $\mathrm{CuBr}_{2}$ (0.1 equiv) and NBS (1.5 equiv) were used, comparable yields of $\mathbf{3 a}$ and $\mathbf{3} \mathbf{b}$ were obtained. However, for $\mathrm{CF}_{3}$-containing substrate 1f, only $5 \%$ yield of $\mathbf{3} \mathbf{f}$ was obtained under the catalytic conditions. No formation of $\mathbf{3 b}$ was observed using NBS without $\mathrm{CuBr}_{2}{ }^{14}$

Furthermore, we were interested in comparing the reaction outcome for a series of dimethyl-substituted nitrosoarenes (1i, $\mathbf{1 j}, \mathbf{1 m}$, and $\mathbf{1 n}$ ). As seen in Schemes 3 and 4, the reactions of 2,5dimethylated nitrosoarene $\mathbf{1 i}$ afforded the para-halogenated products $2 \mathbf{i}$ and $3 \mathbf{i}$ in excellent selectivity. Quite expectedly, substrate $\mathbf{1 j}$ gave an isomeric mixture of ortho-halogenated products $2 \mathbf{j}$ and $3 \mathbf{j}$ with a preference for functionalization at the least hindered position (Schemes 3 and $4, \mathbf{2} \mathbf{j}$ and $\mathbf{3} \mathbf{j}$ ). However, the halogenation of substrates $\mathbf{1 m}$ and $\mathbf{1 n}$ led to rather unexpected outcomes (eqs 1 and 2).

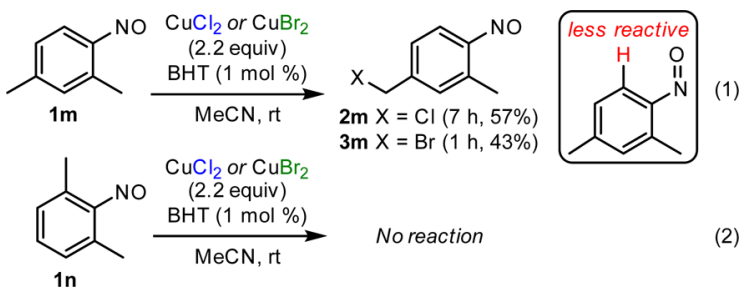

For nitrosoarene $\mathbf{1 m}$, being substituted in the para-position and in one of the ortho-positions with respect to the nitroso group, the benzylic products $2 \mathrm{~m}$ and $3 \mathrm{~m}$ were selectively obtained instead of the expected ortho-halogenated products. We 
speculate that the ortho-position may be less reactive on the basis of the geometry and direction of the nitroso group, ${ }^{15}$ favoring a quinomethide-type of reactivity. The ortho-disubstituted substrate 1 n was in contrast completely unreactive under the applied reaction conditions, possibly due to a low solubility of dimerized 1n. $^{16}$

As seen in Schemes 3 and 4, moderate yields were generally obtained. For certain substrates, e.g., nitrosobenzene, the formation of azoxyarenes was observed, and in most cases $\sim 10 \%$ of the starting material remained unreacted. Formation of polymeric material and sublimation, generally observed for nitrosoarenes, are other possible reasons for the moderate isolated yields. In order to probe for possible regioisomeric products and to acquire more information on the mass balance, the chlorination of $\mathbf{1 b}$ was monitored by ${ }^{1} \mathrm{H}$ NMR (Figure 1 ).

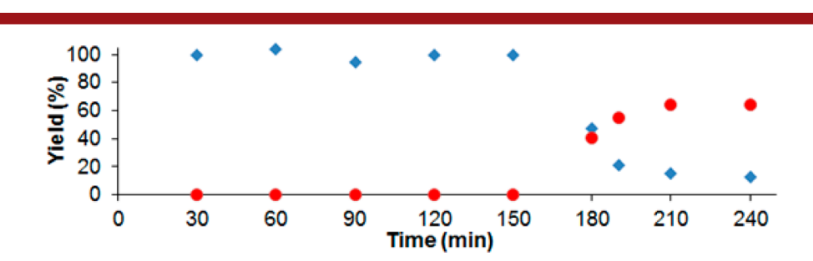

Figure 1. Chlorination of $\mathbf{1 b}$, monitored by ${ }^{1} \mathrm{H}$ NMR (blue $\bullet$, $\mathbf{1 b}$; red $\bullet, 2 \mathbf{b})$.

From the reaction profile above, it can be concluded the reaction took off after a fairly long induction period (in $\mathrm{MeCN}-d_{3}$ at $20{ }^{\circ} \mathrm{C}$ (Figure 1), the reaction was found to require slightly longer time). Moreover, ${ }^{1} \mathrm{H}$ NMR analysis showed that only $80 \%$ of the material could be identified as $\mathbf{1 b}$ or $\mathbf{2} \mathbf{b}$ in the crude reaction mixture. The ${ }^{1} \mathrm{H}$ NMR yield (64\%) was slightly lower than the isolated yield (74\%), which also indicates that complexation of $\mathbf{2 b}$ (and/or $\mathbf{1 b}$ ) with copper could account for some of the remaining material. Furthermore, by comparison with a reference sample of the ortho-chlorinated product, neither ${ }^{1} \mathrm{H}$ NMR nor HPLC analysis of the crude reaction mixture could verify formation of the ortho-regioisomer in any traceable amounts. $^{14}$

In order to demonstrate the versatility of our method, we envisioned that a series of halogenated arenes within the whole landscape of nitrogen oxidation states could be accessed by a one-pot halogenation-reduction/oxidation (Figure 2).

The in situ reduction of the halogenated nitrosoarenes was achieved by the addition of $\mathrm{NaBH}_{4}$ to the halogenation reaction mixture to obtain anilines $\mathbf{4 b}, \mathbf{5 b}$, and $\mathbf{5 f}$ in good yields. Aniline $\mathbf{4 f}$ was found to be unstable under the reaction conditions (Figure 2). Interestingly, the reduction of the nitroso group was found to be more efficient in the presence of the copper salts already

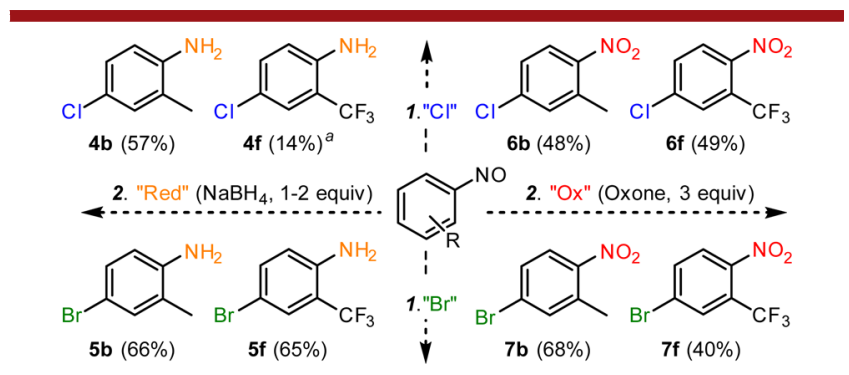

Figure 2. One-pot synthesis of halogenated anilines and nitroarenes: step 1, halogenation; step 2, oxidation/reduction (see the Supporting Information for details). (a) Product was not stable. present in the reaction mixture from the halogenation step. ${ }^{17}$ Furthermore, the oxidation of the nitroso group could efficiently be achieved in a one-pot sequence using Oxone (40-68\% yield, $\mathbf{6 b}, \mathbf{6 f}, \mathbf{7 b}$, and $7 \mathbf{f})$. No regioisomeric products were obtained in the one-pot oxidation or reduction reactions, which further support the high regioselectivity of our halogenation protocol.

Furthermore, we were interested in comparing our results with the halogenation of a selection of electron-rich arenes $(8 \mathbf{a}-\mathbf{c})$ with $\mathrm{CuX}_{2}$ (Scheme 5).

\section{Scheme 5. Halogenation of Electron-Rich Arenes ${ }^{a}$}

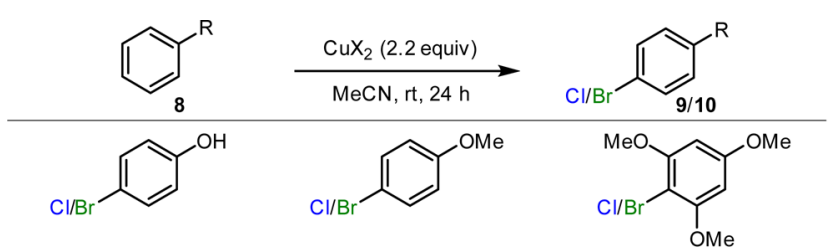

9a $(\mathrm{Cl}: 63 \%)^{b / 10 a}(\mathrm{Br}: 84 \%) \quad 9 b(\mathrm{Cl}: 0 \%) / \mathbf{1 0 b}(\mathrm{Br}: 89 \%) \quad$ 9c $(\mathrm{Cl}: \mathbf{7 8 \%})^{c / 10 c}(\mathrm{Br}: 85 \%)^{a}$

${ }^{a}$ General conditions: arene $8(0.30 \mathrm{mmol})$ and $\mathrm{CuX}_{2}(2.2$ equiv $)$ in $\mathrm{MeCN}(1.2 \mathrm{~mL})$, stirred at $\mathrm{rt}$ for $24 \mathrm{~h} .{ }^{b}$ For 6 days at $70{ }^{\circ} \mathrm{C}$. ${ }^{c}$ Temperature: $50{ }^{\circ} \mathrm{C} .{ }^{d} 2.0$ equiv of $\mathrm{CuBr}_{2}$, time $45 \mathrm{~min}$, isolated with 2,4-dibromo-1,3,5-trimethoxybenzene (ratio: 1.0:0.08).

We found that the brominated derivatives of phenol $(\mathbf{8 a})$ and methoxybenzene derivatives $\mathbf{8 b}, \mathbf{c}$ could be obtained in high yields. Although the corresponding chlorination using $\mathrm{CuCl}_{2}$ worked reasonably well for $\mathbf{8 a}$ and $\mathbf{8 c}$ upon heating, anisole $(\mathbf{8 b})$ did not react at all. These results are very similar to the ones reported in the literature for the halogenation of electron-rich arenes with $\mathrm{Cu}(\mathrm{II})$ salts under oxidative conditions. ${ }^{13 c, g}$ When comparing the halogenation of nitrosoarenes 1 with the results presented in Scheme 5, one can point out a couple of important differences. First, the electron-deficient nitrosoarenes 1 typically required shorter reaction times compared to the electron-rich arenes 8. Moreover, no induction period was observed for the halogenation of electron-rich substrates $\mathbf{8}$ as was seen for the nitrosoarenes $\mathbf{1}$, which may indicate different overall mechanistic pathways.

Based on the observation that nitrosoarenes with EWGs generally required more forcing reaction conditions compared to nitrosoarenes with EDGs, we speculate that the mechanism involves a rate-determining step in which a positive charge is built up. Moreover, since the nitrosoarenes reacted unexpectedly rapid (compared to arenes 8), it is not unlikely that the nitroso group is temporarily converted into a more reactive functional group during the course of the reaction. Indeed the electrophilic bromination of nitrosoarenes with $\mathrm{Br}_{2}$ has been proposed to be initiated by a $\mathrm{HBr}$ addition across the $\mathrm{N}-\mathrm{O}$ bond. ${ }^{8 \mathrm{C}}$ A similar hydroxylamine type of intermediate could also be envisioned in our case as we could observe azoxybenzene derivatives (formed by the condensation of hydroxylamine with a nitrosoarene) as byproducts in the reaction. The second equivalent of the $\mathrm{Cu}$ (II) halide, which was necessary to obtain full conversion, may be important for reoxidizing any hydroxylamine type of intermediates or for the stoichiometric generation of $\mathrm{X}_{2}$ or $\mathrm{HX}$, which are likely to be involved (Scheme 6, A). Alternative mechanisms, such as a nucleophilic attack of a halide anion on a Bambergertype $^{18}$ of nitrenium intermediate (B), or pathways involving radical species (C), cannot be ruled out. Whether BHT is involved in any important redox reactions, or serves as a radical scavenger to prevent unproductive radical pathways, remains unclear. 
Scheme 6. Proposed Halogenation Intermediates

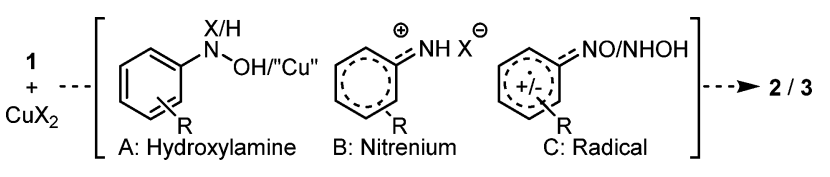

In short, we have developed an operationally simple paraselective method for the bromination and chlorination of a wide range of nitrosoarenes with $\mathrm{Cu}$ (II) halides. The resulting nitroso derivatives were, in a one-pot procedure, conveniently transformed into the corresponding anilines and nitroarenes. Thus, with a limited set of starting compounds and with an easy-toexecute method, a range of halogenated, nitrogen-functionalized products can be obtained in high regioisomeric purity and decent yields.

\section{ASSOCIATED CONTENT}

\section{S Supporting Information}

The Supporting Information is available free of charge on the ACS Publications website at DOI: 10.1021/acs.orglett.5b03198.

Experimental procedures and characterization data (PDF)

\section{AUTHOR INFORMATION}

\section{Corresponding Author}

*E-mail: nicklas.selander@su.se.

Notes

The authors declare no competing financial interest.

\section{ACKNOWLEDGMENTS}

This work was supported by the Swedish Research Council (VR) and the Lars Hierta Memorial Foundation.

\section{REFERENCES}

(1) For reviews, see: (a) Vančik, H. Aromatic C-Nitroso Compounds; Springer: Dordrecht, 2013. (b) Yamamoto, H.; Momiyama, N. Chem. Commun. 2005, 3514. (c) Lee, J.; Chen, L.; West, A. H.; Richter-Addo, G. B. Chem. Rev. 2002, 102, 1019. (d) Zuman, P.; Shah, B. Chem. Rev. 1994, 94, 1621. (e) Gowenlock, B. G.; Lüttke, W. Q. Rev., Chem. Soc. 1958, 12, 321. (f) Yamamoto, H.; Kawasaki, M. Bull. Chem. Soc. Jpn. 2007, 80, 595.

(2) (a) Molander, G. A.; Cavalcanti, L. N. J. Org. Chem. 2012, 77, 4402. (b) Bosch, E.; Kochi, J. K. J. Org. Chem. 1994, 59, 5573.

(3) (a) Rück-Braun, K.; Priewisch, B. Nitrosoarenes. In Science of Synthesis: Houben-Weyl Methods of Molecular Transformations; Ramsden, C. A., Ed.; Thieme: Stuttgart, 2007; Vol. 31b, p 1321. (b) Priewisch, B.; Rück-Braun, K. J. Org. Chem. 2005, 70, 2350.

(4) Selected examples: (a) Kyne, R. E.; Ryan, M. C.; Kliman, L. T.; Morken, J. P. Org. Lett. 2010, 12, 3796. (b) Du, J.; Yang, Y.; Feng, H.; Li, Y.; Zhou, B. Chem. - Eur. J. 2014, 20, 5727. (c) Dhayalan, V.; Sämann, C.; Knochel, P. Chem. Commun. 2015, 51, 3239. (d) Li, Y.; Chakrabarty, S.; Studer, A. Angew. Chem., Int. Ed. 2015, 54, 3587.

(5) Selected examples: (a) Momiyama, N.; Yamamoto, H. Org. Lett. 2002, 4, 3579. (b) Momiyama, N.; Yamamoto, H. Angew. Chem., Int. Ed. 2002, 41, 2986. (c) Brown, S. P.; Brochu, M. P.; Sinz, C. J.; MacMillan, D. W. J. Am. Chem. Soc. 2003, 125, 10808. (d) Momiyama, N.; Yamamoto, H. J. Am. Chem. Soc. 2003, 125, 6038. (e) Yamamoto, Y.; Momiyama, N.; Yamamoto, H. J. Am. Chem. Soc. 2004, 126, 5962. (f) Janey, J. M. Angew. Chem., Int. Ed. 2005, 44, 4292. (g) Kano, T.; Ueda, M.; Takai, J.; Maruoka, K. J. Am. Chem. Soc. 2006, 128, 6046.

(6) Selected examples: (a) Penoni, A.; Volkmann, J.; Nicholas, K. M. Org. Lett. 2002, 4, 699. (b) Yamamoto, Y.; Yamamoto, H. J. Am. Chem. Soc. 2004, 126, 4128. (c) Yamamoto, Y.; Yamamoto, H. Angew. Chem., Int. Ed. 2005, 44, 7082. (d) Jana, C. K.; Studer, A. Chem. - Eur. J. 2008,
14, 6326. (e) Dochnahl, M.; Fu, G. C. Angew. Chem., Int. Ed. 2009, 48, 2391. (f) Yang, L.; Tan, B.; Wang, F.; Zhong, G. J. Org. Chem. 2009, 74, 1744. (g) Pagar, V. V.; Jadhav, A. M.; Liu, R.-S. J. Am. Chem. Soc. 2011, 133, 20728. (h) Chen, C.-H.; Tsai, Y.-C.; Liu, R.-S. Angew. Chem., Int. Ed. 2013, 52, 4599. (i) Ran, R.-Q.; Xiu, S.-D.; Li, C.-Y. Org. Lett. 2014, 16, 6394. (j) Vemula, N.; Stevens, A. C.; Schon, T. B.; Pagenkopf, B. L. Chem. Commun. 2014, 50, 1668. (k) Otley, K. D.; Ellman, J. A. J. Org. Chem. 2014, 79, 8296. (l) Eberlin, L.; Carboni, B.; Whiting, A. J. Org. Chem. 2015, 80, 6574.

(7) Adam, W.; Krebs, O. Chem. Rev. 2003, 103, 4131.

(8) For classical electrophilic halogenation, see: (a) Ingold, C. K. J. Chem. Soc., Trans. 1925, 127, 513. (b) Le Févre, R. J. W. J. Chem. Soc. 1931, 810. (c) Robertson, P. W.; Hitchings, T. R.; Will, G. M. J. Chem. Soc. 1950, 808 .

(9) For nucleophilic substitutions with amines, see: (a) Lipilin, D. L.; Churakov, A. M.; Ioffe, S. L.; Strelenko, Y. A.; Tartakovsky, V. A. Eur. J. Org. Chem. 1999, 29. (b) Gornostaev, L. M.; Bocharova, E. A.; Geets, N. V. Russ. J. Org. Chem. 2006, 42, 1289.

(10) For transformations of both the nitroso-group and the aromatic ring, see: (a) Pilepić, V.; Lovrek, M.; Vikić-Topić, D.; Uršić, S. Tetrahedron Lett. 2001, 42, 8519. (b) Seayad, J.; Patra, P. K.; Zhang, Y.; Ying, J. Y. Org. Lett. 2008, 10, 953.

(11) For selected examples, see: (a) Dick, A. R.; Hull, K. L.; Sanford, M. S. J. Am. Chem. Soc. 2004, 126, 2300. (b) Kalyani, D.; Dick, A. R.; Anani, W. Q.; Sanford, M. S. Org. Lett. 2006, 8, 2523. (c) Mei, T.-S.; Giri, R; Maugel, N.; Yu, J.-Q. Angew. Chem., Int. Ed. 2008, 47, 5215. (d) Zhao, X.; Dimitrijević, E.; Dong, V. M. J. Am. Chem. Soc. 2009, 131, 3466. (e) Dudnik, A. S.; Chernyak, N.; Huang, C.; Gevorgyan, V. Angew. Chem., Int. Ed. 2010, 49, 8729. (f) Bedford, R. B.; Haddow, M. F.; Mitchell, C. J.; Webster, R. L. Angew. Chem., Int. Ed. 2011, 50, 5524. (g) Schröder, N.; Wencel-Delord, J.; Glorius, F. J. Am. Chem. Soc. 2012, 134, 8298. (h) Rodriguez, R. A.; Pan, C.-M.; Yabe, Y.; Kawamata, Y.; Eastgate, M. D.; Baran, P. S. J. Am. Chem. Soc. 2014, 136, 6908. (i) Samanta, R. C.; Yamamoto, H. Chem. - Eur. J. 2015, 21, 11976. (j) Song, S.; Sun, X.; Li, X.; Yuan, Y.; Jiao, N. Org. Lett. 2015, 17, 2886.

(12) For reviews, see: (a) Wendlandt, A. E.; Suess, A. M.; Stahl, S. S. Angew. Chem., Int. Ed. 2011, 50, 11062. (b) Allen, S. E.; Walvoord, R. R; Padilla-Salinas, R.; Kozlowski, M. C. Chem. Rev. 2013, 113, 6234. (c) McCann, S. D.; Stahl, S. S. Acc. Chem. Res. 2015, 48, 1756.

(13) (a) Crocker, H. P.; Walser, R. J. Chem. Soc. C 1970, 1982. (b) Chen, X.; Hao, X.-S.; Goodhue, C. E.; Yu, J.-Q. J. Am. Chem. Soc. 2006, 128, 6790. (c) Menini, L.; Gusevskaya, E. V. Chem. Commun. 2006, 209. (d) Menini, L.; Gusevskaya, E. V. Appl. Catal., A 2006, 309, 122. (e) Menini, L.; Parreira, L. A.; Gusevskaya, E. V. Tetrahedron Lett. 2007, 48, 6401. (f) Menini, L.; da Cruz Santos, J. C.; Gusevskaya, E. V. Adv. Synth. Catal. 2008, 350, 2052. (g) Yang, L.; Lu, Z.; Stahl, S. S. Chem. Commun. 2009, 6460. (h) King, A. E.; Huffman, L. M.; Casitas, A.; Costas, M.; Ribas, X.; Stahl, S. S. J. Am. Chem. Soc. 2010, 132, 12068. (i) Wang, H.; Wen, K.; Nurahmat, N.; Shao, Y.; Zhang, H.; Wei, C.; Li, Y.; Shen, Y.; Sun, Z. Beilstein J. Org. Chem. 2012, 8, 744. (j) Mo, S.; Zhu, Y.; Shen, Z. Org. Biomol. Chem. 2013, 11, 2756. (k) Suess, A. M.; Ertem, M. Z.; Cramer, C. J.; Stahl, S. S. J. Am. Chem. Soc. 2013, 135, 9797. (1) Li, B.; Liu, B.; Shi, B.-F. Chem. Commun. 2015, 51, 5093.

(14) See the Supporting Information for details.

(15) Gowenlock, B. G.; Cameron, M.; Boyd, A. S. F.; Al-Tahou, B. M.; McKenna, P. Can. J. Chem. 1994, 72, 514.

(16) Holmes, R. R. J. Org. Chem. 1964, 29, 3076.

(17) He, Y.; Zhao, H.; Pan, X.; Wang, S. Synth. Commun. 1989, 19, 3047.

(18) (a) Bamberger, E. Ber. Dtsch. Chem. Ges. 1894, 27, 1548. (b) Bamberger, E.; Büsdorf, H.; Szolayski, B. Ber. Dtsch. Chem. Ges. 1899, 32, 210. (c) Yamabe, S.; Zeng, G.; Guan, W.; Sakaki, S. Beilstein J. Org. Chem. 2013, 9, 1073. 